\title{
Report from the Affiliated Groups Meeting, Southampton, 27-28 January 2000
}

\section{History of the Affiliated Groups}

\section{Dr Sarah Randall, Consultant in Reproductive Health, Ella Gordon Unit, Portsmouth}

- Local groups started with the development of the FPA clinics in the 1950s.

- The introduction of pills and coils generated the need for meetings to discuss issues. Pill companies offered sponsorship.

- Local groups were informal; some with doctors only and some combined with nurses.

- In the late 1960s, the FPA arranged for two doctors from each region to meet annually.

- NAFPD was formed in 1974. The local groups became affiliated and the annual meetings continued.

- 1974 Saw the introduction of free contraception and the hand-over of clinics to the NHS with doctors overseen by the Public Health Department.

- In 1993 there were 16 groups across the UK.

- In 1993 the Faculty of Family Planning and Reproductive Health Care was founded and continued to support the local groups, which became affiliated to the Faculty.

- Now there are 24 groups, covering most of the UK, and representation from the Brook and the Society of Consultants in Reproductive Health Care.

- The work of the Affiliated Groups is much appreciated locally and nationally.

\section{The Role of the local Affiliated Groups and the annual Affiliated Groups Meeting of the Faculty}

Dr Helen Massil, Consultant in Family Planning and Reproductive Health Care, Community Health South London Trust.

- The Affiliated Groups vary in membership size (10 250 members), but all report that they are either increasing in size or remain stable.

- The main role of the Affiliated Groups is to organise local meetings which provide reproductive healthcare updating, as well as feedback from the annual Affiliated Groups Meeting of the Faculty.

- The local Affiliated Groups continue to send two representatives to the annual Affiliated Groups Meeting of the Faculty.
- All Affiliated Groups agreed with the conclusion from the annual Affiliated Groups Meeting in January 1999, that the representatives to the annual meeting should concentrate on active participation in discussion with the Faculty. Updating should be left to the local meetings and other CPD activities. The most commonly sighted topics for future annual meetings included service-related issues and clinical governance.

\section{Peer Review workshop}

Fran Reader, Honorary Editor, British Journal of Family Planning

- Peer review acts as a quality assurance system guiding editorial decisions.

- The peer reviewer assesses: the scientific merit of the paper; the relevance to Journal readership; the appropriateness or accuracy of the methodology, results, discussion and conclusions; the clarity of style and presentation.

- Peer review skills include - making time for the task; critical reading skills; knowledge of the topic and related publications; the ability to give constructive criticism substantiated with references where appropriate.

Recommended reading for peer reviewers

Greenhalgh T. How to read a paper. London: BMJ Books, 1997

Godlee F, Jefferson T. Peer review in health sciences. London: BMJ Books, 1999.

O'Brien PMS, Broughton Pipkin F. Introduction to research methodology. London: RCOC Press, 1999

\section{MFFP Examination}

\section{Dr Meera Kishen, Member of Faculty Examination Committee}

Dr Kishen gave a brief introduction about the structure of the examination and the validation process. The delegates then split into two workshop groups to explore further the Objective Structured Clinical Examination (OSCE) and the Modified Essay Question (MEQ) components of the Part 2 examination.

\section{- OSCE}

This is a system of assessment stations (10 for the MFFP) where a range of practical skills is assessed through an objective marking system. There are two main types of station in the examination - interactive (including roleplay) and written. A group of examiners work to develop the question, answers and the marking schedules. Two delegate groups led by Dr Meera Kishen and Dr Yvonne Stedman worked on developing and answering/ marking two sample questions for the MFFP examination.

\section{- $M E Q$}

In this written section the candidate is given a number of clinical scenarios relating to sexual health issues. These may be straightforward clinical situations or more complex ones involving management or audit themes. For each scenario there are three questions which require an answer in the form of a bulleted list. These questions and answers, along with marking schedules, are developed by a group of examiners working in a team. Two delegate groups led by Dr Sheila Merchant and Dr Lesley Batchelor had a go at answering a question that was deliberately worded badly, and then set about improving the question to make it less ambiguous.

The general consensus opinion was that the questions were very relevant to the practical aspect of our work and being an examiner could be quite good fun! 